\title{
Role of the HIF-1 signaling pathway in chronic obstructive pulmonary disease
}

\author{
XIANG FU and FENGLING ZHANG \\ Department of Respiratory Medicine, The No. 5 Hospital of Xiamen, Xiamen, Fujian 361100, P.R. China
}

Received November 15, 2017; Accepted May 25, 2018

DOI: $10.3892 /$ etm.2018.6785

\begin{abstract}
Chronic obstructive pulmonary disease (COPD) is the most common cause of chronic morbidity and mortality. However, the molecular mechanisms underlying COPD remain largely unknown. The purpose of the present study was to investigate the expression patterns of hypoxia-inducible factor $1 \alpha(\mathrm{HIF}-1 \alpha)$, vascular endothelial growth factor (VEGF), and VEGF receptor 2 (R2) in regard to the HIF-1 signaling pathway in COPD. The expressions of HIF-1 $\alpha$, VEGF and VEGFR2 were examined and quantified in the human lung tissues of 102 subjects with a defined smoking status, with or without COPD. The expressions of HIF-1 $\alpha$, VEGF and VEGFR2 were observed to be increased in the lung tissues collected from smoking COPD subjects when compared with those tissues from smoking subjects without COPD and non-smoking subjects without COPD. The expression of HIF-1 $\alpha$ was shown to be positively associated with the expression of VEGF and VEGFR2. In addition, increased expression of HIF-1 $\alpha$, VEGF and VEGFR2 reflected the disease severity of COPD. The key findings obtained from the present study indicated that high expression of HIF-1 $\alpha$, VEGF and VEGFR2 may be associated with decreased lung function and reduced quality of life, contributing to disease progression in COPD.
\end{abstract}

\section{Introduction}

Chronic obstructive pulmonary disease (COPD) is characterized by progressive, irreversible obstruction of airflow, with pathological changes in the lung and extrapulmonary comorbidities, which are defined in the 2011 version of Global Initiative for Chronic Obstructive Lung Disease (GOLD) (1). Airflow obstruction is commonly caused by airway diseases

Correspondence to: Dr Xiang Fu, Department of Respiratory Medicine, The No. 5 Hospital of Xiamen, 101 Min'an Road, Xiamen, Fujian 361100, P.R. China

E-mail: fuxiang7896@163.com

Key words: chronic obstructive pulmonary disease, hypoxia-inducible factor $1 \alpha$ signaling pathway, hypoxia inducible factor-1 $\alpha$, vascular endothelial growth factor, vascular endothelial growth factor receptor or emphysema (2), and it is associated with body mass index (BMI) (3) and cardiovascular diseases (4). According to an estimation by the World Health Organization, COPD is the fourth leading cause of death globally, and it causes approximately 3,000,000 deaths annually (5). The severity of COPD is assessed on the basis of forced expiratory volume over $1 \mathrm{sec}$ (FEV1), and spirometry is usually used as the gold standard (6). The Modified Medical Research Council (mMRC) scale and the COPD Assessment Test (CAT) scores are commonly performed to evaluate the severity of dyspnea and quality of life for COPD patients (7). The most common risk factor for COPD is inhalation of toxic substances, which causes inflammation in the lung, especially cigarette smoke, as well as inhaled smoke from the burning of biomass fuels (8). Only $25 \%$ of smokers suffer from COPD, which indicates that other risk factors or molecular biomarkers may be involved in the occurrence and progression of COPD (9), although theses remain to be determined.

Hypoxia-inducible factor 1 (HIF-1) is a transcriptional activator induced by hypoxia, and a modulator of oxygen homeostasis and physiological responses $(10,11)$. HIF-1 mediates oxygen delivery through its effects on vascular remodeling and angiogenesis, and oxygen utilization through involvement in redox homeostasis and glucose metabolism (12). Vascular endothelial grow th factor (VEGF), whose expression is induced by $\mathrm{HIF}-1 \alpha$, is a potent regulator of angiogenesis and vascular permeability. VEGF has shown to be involved in the pathogenesis of COPD and HIF-1 $\alpha$-regulated VEGF overexpression may be a characteristic of chronic bronchitis (13). VEGF and its receptors VEGFR-1 (Flt-1) and VEGFR-2 (KDR/Flk-1) could play a role in tissue remodeling and angiogenesis in COPD (14). We proposed the hypothesis that the HIF-1 $\alpha$ signaling pathway may be associated with COPD progression. We examined and quantified the expression of HIF-1 $\alpha$, VEGF and VEGFR2 in human lung tissues from 102 subjects with a defined smoking status, with or without COPD. A comparative study was performed using non-smoking subjects without COPD, smoking subjects without COPD, and smoking COPD subjects. In the present study, the expressions of HIF-1 $\alpha$, VEGF and VEGFR2 was found to be increased in the lung tissues collected from smoking COPD subjects compared with those tissues from smoking subjects without COPD and non-smoking subjects without COPD. Increased expressions of HIF-1 $\alpha$, VEGF and VEGFR2 reflected the disease severity of COPD. 


\section{Materials and methods}

Ethics statement. The present study was performed with the approval of the Ethics Committee of the No. 5 Hospital of Xiamen (Xiamen, China). Written informed consent and the required documentation were obtained from each patient and respective guardians prior to the study.

Tissue specimens. A total of 102 lung tissue specimens were collected from subjects who received surgical resection at the Department of Thoracic Surgery of the No. 5 Hospital of Xiamen from June 2015 to December 2016. These lung tissue specimens had a known smoking status, with or without COPD according to pulmonary function test. Smoking history was recorded as required by the Global Initiative for Chronic Obstructive Lung Disease (GOLD) (15) and Guidelines for Diagnosis and Treatment of Chronic Obstructive Pulmonary Disease (16) specified by the COPD group of affiliate of respiratory disease in the Chinese Medical Association. The included subjects met all of the following requirements: i) Patients who were ready to receive pulmonary surgery; ii) patients who were diagnosed with COPD based on the Guidelines for Diagnosis and Treatment of Chronic Obstructive Pulmonary Disease (2013 edition), namely, those with a post-bronchodilator FEV1 $<80 \%$ predicted, FEV1/forced vital capacity (FVC) ratio $<70 \%$ and FEV1 $>1.0 \mathrm{~L}$, and pulmonary surgery was feasible; and iii) patients who did not undergo any radiotherapy or chemotherapy before the pulmonary surgery. Subjects were excluded from the enrollment if they were diagnosed with: i) Non-COPD pulmonary diseases such as bronchial asthma, bronchiectasis, interstitial pulmonary fibrosis or diffuse panbronchiolitis; ii) cognitive impairment, obnubilation or senile dementia; iii) critical systemic diseases such as cardiac disease or liver failure; and iv) a history of drug abuse or alcohol dependence. The lung tissues enrolled in this study were fresh tissues without focal infiltration, as examined with the naked eye. They were all collected from the lung borders ( $>5 \mathrm{~cm}$ away from the lesions). The tissues were washed in D-Hanks solution containing penicillin and streptomycin. Some lung tissues were stored in liquid nitrogen and some were conventionally fixed and embedded in paraffin, followed by slicing.

Clinical outcomes. Lung functions were evaluated before surgery by a pirometer (Jaeger Master Screen; Erich Jaeger $\mathrm{GmbH}$, Hoechberg, Germany). A week before surgery, the same parameters of lung functions were measured, including FVC, FEV1, predicted FEV1\% (FEV1\% pred), FEV1/FVC and peak expiratory flow (PEF). Pulmonary function tests were performed $15 \mathrm{~min}$ after salbutamol inhalation $(20 \mu \mathrm{g})$, and bronchodilators were not administered $24 \mathrm{~h}$ before the test. The quality of life was assessed for the COPD patients using the CAT questionnaire (17). The patients gave scores (0-5) for each item according to their own conditions, and 0 point represented the lowest degree of severity, while 5 points represented the highest degree. Higher scores represented a lower quality of life. The mMRC dyspnea scale was applied to grade the severity of dyspnea of COPD patients, and Grade 0 represented the slightest dyspnea, while Grade 4 represented the worst dyspnea.
Hematoxylin and eosin $(H \& E)$ staining. Fresh lung tissue blocks were fixed in formalin, embedded in paraffin and sliced (3-5 $\mathrm{mm}$ thickness). The sections were deparaffinized using xylene and dehydrated in graded ethanol. Then sections were stained with hematoxylin for $10 \mathrm{~min}$ before rinsing under running water. After differentiation in $1 \%$ ethanol-hydrochloric acid for $30 \mathrm{sec}$, the sections were immersed in tap water for $15 \mathrm{~min}$, followed by counterstaining in eosin for $2 \mathrm{~min}$. After that, sections were conventionally dehydrated, permeabilized and mounted. Images of the tissues were acquired and analyzed by two senior pathologists with a double-blind method.

Immunohistochemistry. The lung tissues were embedded in paraffin and sliced to serial sections of $4 \mu \mathrm{m}$. Then the sections were baked at $70^{\circ} \mathrm{C}$ for $15 \mathrm{~min}$ and dehydrated in graded ethanol. Endogenous peroxidase activity was quenched with $\mathrm{H}_{2} \mathrm{O}_{2}$, followed by washing with phosphate-buffered saline (PBS) 3 times (5 min per wash). Normal goat serum was employed to incubate the sections for $15 \mathrm{~min}$ at room temperature. Primary antibodies (20-30 $\mu$ l) of HIF-1 $\alpha$ (1:100; Wuhan Boster Biological Technology, Ltd., Wuhan, China), VEGF (working solution; Zymed South San Francisco, CA, USA) and VEGFR2 (1:100; Wuhan Boster Biological Technology, Ltd.) diluted by PBS were used in the sections, incubated at $4^{\circ} \mathrm{C}$ overnight. PBS, instead of the primary antibody, was used as negative control. After washing for 3 times with PBS, biotinylated ready-to-use secondary antibodies were added and incubated for $20 \mathrm{~min}$ at $37^{\circ} \mathrm{C}$. Horseradish peroxidase-labeled streptavidin working solution was added to the incubation for $20 \mathrm{~min}$ at $37^{\circ} \mathrm{C}$. Diaminobenzidine (DAB; Zhongshan Goldenbridge Biotechnology Co., Ltd., Beijing, China) was used to develop color for 3-5 min. Then, the sections were fully rinsed under running water, followed by a 5 -min counterstain using hematoxylin. After that, the sections were dehydrated, permeabilized in xylene and mounted, followed by microscopic examination. The images were reviewed by two senior pathologists with a double-blind method. The numbers of cells with positive expression and tumor cells were calculated by computer-assisted microscope image analysis. The positive expression of HIF-1 $\alpha$ located in the nucleus or cytoplasm was demonstrated by yellow/brown color. The VEGF protein was mainly located in the cytoplasm, and cells with yellow brown particles in the cytoplasm were determined as positive cells. The expression of VEGFR 2 was primarily located in the membrane and cytoplasm, with yellow/brown particles representing positive expression. Five high power fields (magnification, $\mathrm{x} 400$ ) were randomly selected for each section. A total of 200 cells were counted in each field, and the semi-quantitative integral method (18) was adopted to determine the results. The number of positive cells was graded as $0,1(<25 \%), 2(25-75 \%), 3(>75 \%)$, and the intensity of the dye color was graded as 1 (weak expression, light yellow), 2 (moderate expression, yellow brown) or 3 (strong expression, brown). The two scores were multiplied together and the specimens were classified as one of 4 levels: $0-1(-)$ for negative expression, 2-3 ( \pm ) for weak positive expression, 4-6 (+) for moderate positive expression or 7-9 (++) for strong positive expression. '-' and ' \pm ' were combined to ' - ', and ' + ' and ' ++ ' to ' + ', in order to simplify data analysis. The immunohistochemical images were analyzed with the HPIAS-1000 
Table I. Baseline characteristics of non-smoking non-COPD, smoking non-COPD and smoking COPD patients.

\begin{tabular}{|c|c|c|c|c|}
\hline Characteristic & NS group (n) & S group (n) & COPD group (n) & P-value \\
\hline Sex & & & & 0.298 \\
\hline Male & 20 & 23 & 26 & \\
\hline Female & 14 & 11 & 8 & \\
\hline Age (years) & $56.32 \pm 8.34$ & $58.65 \pm 6.87$ & $60.32 \pm 8.20$ & 0.114 \\
\hline Age distribution (years) & & & & 0.089 \\
\hline$<60$ & 30 & 16 & 17 & \\
\hline$\geq 60$ & 14 & 18 & 19 & \\
\hline BMI $\left(\mathrm{kg} / \mathrm{m}^{2}\right)$ & $23.65 \pm 7.89$ & $23.01 \pm 6.89$ & $22.18 \pm 6.41$ & 0.693 \\
\hline Smoking index & 0 & $771.16 \pm 109.87$ & $876.54 \pm 118.28$ & $<0.05$ \\
\hline History of alcohol use & & & & 0.365 \\
\hline Yes & 6 & 8 & 11 & \\
\hline No & 28 & 26 & 23 & \\
\hline Family history & & & & 0.004 \\
\hline Yes & 2 & 6 & 13 & \\
\hline No & 32 & 28 & 21 & \\
\hline
\end{tabular}

$\chi^{2}$ test was used to analyze the categorical data (sex, age distribution, history of alcohol use and family history). Data are presented as the $\mathrm{n}$ number, or as the mean \pm standard deviation. COPD, chronic obstructive pulmonary disease; BMI, body mass index; NS group, non-smoking non-COPD group; S group, smoking non-COPD group; COPD group, smoking COPD group.

high-resolution color image processing system. Five fields were selected at random, and ten cells were selected in each field. The absorbance values (A) of the yellow/brown or brown positive particles represented the expression of HIF-1 $\alpha$, VEGF and VEGFR2.

Western blot analysis. The concentration of proteins extracted from lung tissues was determined by the bicinchoninic acid (BCA) Protein Assay kit (Wuhan Boster Biological Technology, Ltd.) according to the manufacturer's instructions. Extracted proteins were mixed with the loading buffer, boiled for $10 \mathrm{~min}$ at $95^{\circ} \mathrm{C}$, and then $30 \mu \mathrm{g}$ of protein was added to each well. Then $10 \%$ polyacrylamide gel electrophoresis (Wuhan Boster Biological Technology, Ltd.) was performed to separate proteins with voltage transferred from 80 to $120 \mathrm{~V}$. Then, the proteins were transferred onto polyvinylidene fluoride membranes by wet transfer with transmembrane voltage of $100 \mathrm{mV}$ for 45-70 min. The membrane was blocked with 5\% bovine serum albumin for $1 \mathrm{~h}$ and then independently incubated with diluted (1:100) primary antibodies, rabbit anti-HIF-1 $\alpha$, VEGF, and VEGFR2 antibodies (Santa Cruz Biotechnology, Inc., Santa Cruz, CA, USA) at $4^{\circ} \mathrm{C}$ for $12 \mathrm{~h}$. $\beta$-actin (1:200) was set as the internal reference, purchased from Santa Cruz Biotechnology, Inc. The membranes were washed with Tris-buffered saline with Tween-20 (TBST) solution 3 times ( 5 min per wash), and incubated with the secondary antibodies for $1 \mathrm{~h}$ at room temperature. After membrane washing 3 times $(5 \mathrm{~min}$ per wash) and coloration, the samples were then developed using a Bio-Rad Gel Doc EZ Imager (Bio-Rad Laboratories, Inc., Hercules, CA, USA). The gray values of the target bands were analyzed using ImageJ software (National Institutes of Health, Bethesda, MD, USA). The experiment was repeated three times and the data were averaged.
Statistical analysis. SPSS 22.0 software (IBM Corp., Armonk, NY, USA) was used for data analyses. Quantitative data were expressed as the mean \pm standard deviation. Comparisons among multiple groups were carried out by one-way analysis of variance test with the post hoc Student-Newman-Keuls test, and pairwise comparisons of the experimental groups by t-test. Qualitative and quantitative analyses were performed using Spearman's rank correlation analysis and Pearson correlation analysis. $\mathrm{P}<0.05$ was considered to indicate a statistically significant difference.

\section{Results}

Baseline characteristics of subjects with defined smoking status, with or without COPD. Among non-smoking subjects without COPD, smoking subjects without COPD, and smoking COPD subjects, there were no significant differences in sex, mean age, age distribution, BMI and history of alcohol use (all P>0.05). Compared with non-smoking subjects without COPD, smoking subjects with COPD and without COPD showed a higher smoking index $(\mathrm{P}<0.05)$. Smoking COPD subjects exhibited a higher rate of COPD family history than non-smoking subjects without COPD and smoking subjects without COPD (both $\mathrm{P}<0.05$; Table I).

Decreased lung function in smoking COPD subjects. Non-smoking subjects without COPD and smoking subjects with or without COPD were compared on PF (pulmonary function) (Table II). The changes in PF-related indicators suggested that smoking COPD subjects were significantly different from non-smoking subjects without COPD and smoking subjects without COPD with respect to FEV1, FEV1\% pred, FVC\% pred and $\mathrm{PEF} \%$ pred (all $\mathrm{P}<0.05$ ), while no difference was 

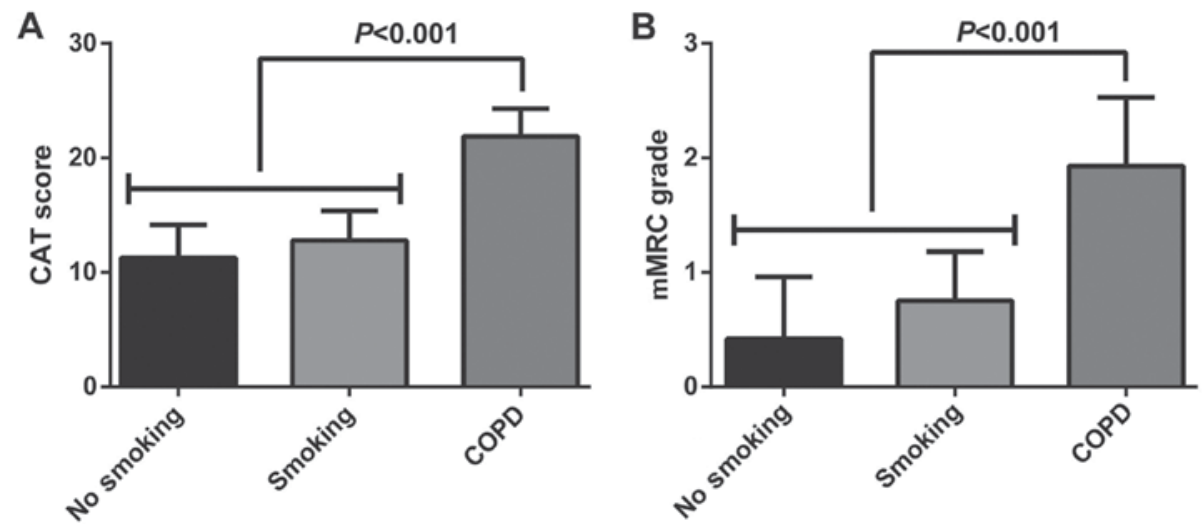

Figure 1. Smoking COPD subjects exhibited (A) reduced quality of life (reflected by CAT scores) and (B) an increased degree of dyspnea (reflected by mMRC grades). $\mathrm{P}<0.001$, as indicated. COPD, chronic obstructive pulmonary disease; mMRC, Modified Medical Research Council scale; CAT, COPD Assessment Test.

Table II. Comparisons between the indicators of the pulmonary function test among the non-smoking non-COPD, smoking non-COPD and smoking COPD patients.

\begin{tabular}{lccc}
\hline Indicator & NS group & S group & COPD group \\
\hline FEV1 (1) & $2.39 \pm 0.38$ & $2.31 \pm 0.33$ & $1.90 \pm 0.42^{\mathrm{a}, \mathrm{b}}$ \\
FEV1\% pred & $94.86 \pm 8.69$ & $93.65 \pm 8.63$ & $65.98 \pm 12.01^{\mathrm{a}, \mathrm{b}}$ \\
FVC\% pred & $98.53 \pm 12.65$ & $95.13 \pm 8.87$ & $75.36 \pm 14.02^{\mathrm{a}, \mathrm{b}}$ \\
FEV1/FVC\% & $80.11 \pm 7.02$ & $78.56 \pm 5.34$ & $66.18 \pm 3.90^{\mathrm{a}, \mathrm{b}}$ \\
PEF\% pred & $92.60 \pm 23.05$ & $89.61 \pm 25.99$ & $58.02 \pm 17.70^{\mathrm{a}, \mathrm{b}}$ \\
\hline
\end{tabular}

Data are presented as the mean \pm standard deviation. ${ }^{\text {aP }}<0.05$ vs. NS group; ${ }^{b} \mathrm{P}<0.05$ vs. $\mathrm{S}$ group. $\mathrm{COPD}$, chronic obstructive pulmonary disease; FEV1, forced expiratory volume in 1 sec; pred, predicted; FVC, forced vital capacity; PEF, peak expiratory flow; NS group, non-smoking non-COPD group; S group, smoking non-COPD group; COPD group, smoking COPD group.

found between non-smoking subjects without COPD and smoking subjects without COPD (all P>0.05).

Quality of life reductions and increases in degree of dyspnea in smoking COPD subjects. Comparisons of CAT scores and mMRC grades among non-smoking subjects without COPD, and smoking subjects with or without COPD (Fig. 1) demonstrated that the CAT scores in non-smoking subjects without COPD, smoking subjects without COPD and smoking COPD subjects were $11.25 \pm 2.61,14.03 \pm 2.72$ and $21.90 \pm 2.42$, respectively; and the mMRC grades were $0.42 \pm 0.54,0.76 \pm 0.43$ and $1.93 \pm 0.75$, respectively. Compared with non-smoking subjects without COPD and smoking subjects without COPD, smoking COPD subjects exhibited higher CAT scores and mMRC grades $(\mathrm{P}<0.05)$, whereas COPD subjects both smoking and non-smoking did not differ significantly $(\mathrm{P}>0.05)$.

Morphological changes in the lung tissues. In non-smoking subjects without COPD (Fig. 2A and D), complete alveoli with uniform sizes and thin walls were observed. Neither obvious congestion nor bleeding was identified. The alveolar cavity showed few inflammatory cells and extracellular matrix degradation was not significant. The bronchial mucosal folds were complete and no exudation in the bronchial lumen or few inflammatory cells in the wall were observed. In smoking subjects without COPD (Fig. 2B and E), S group of alveolar septum and pulmonary scattered inflammatory cells, but no smoke particles, vascular intimal and outer membrane thickening; damage, degeneration and necrosis of ciliated columnar epithelium were partially visible on the airway wall; mild squamous metaplasia, mild hyperplasia, fracture of the smooth muscle of the airway wall and lead to a small number of inflammatory cell infiltration. In smoking COPD subjects (Fig. 2C and F), inflammatory cell infiltration in the bronchial wall and pulmonary, pigmentation in subregion; cilia desquamating and goblet epithelium cells metaplasia in the lung tissues. The alveolar wall becomes thinner or disappearing and some alveolar rupture and enlargement of the alveolar cavity. The airway wall visible ciliated columnar epithelial degeneration, necrosis and shedding; wall and surrounding vascular tissue infiltrated inflammatory cells; a large amount of carbon deposited near the tube wall.

Increased expression of HIF-1 $\alpha, V E G F$ and VEGFR2 in lung tissues collected from smoking COPD subjects. HIF-1 $\alpha$ was mainly expressed in the cytoplasm and nucleus (Fig. 3A). The expression of HIF-1 $\alpha$ was significantly higher in smoking COPD subjects compared with the non-smoking and smoking subjects without COPD (both $\mathrm{P}<0.05$ ). VEGF was mainly expressed in the cytoplasm (Fig. 3B). The expression of VEGF was significantly increased in the smoking COPD subjects compared with the subjects without COPD, both non-smoking and smoking (both $\mathrm{P}<0.05$ ). The expression of VEGFR2 was also mainly found to be in the cytoplasm and on the membrane (Fig. 3C). The expression of VEGFR2 was significantly higher in smoking COPD subjects compared with the non-smoking subjects without COPD and smoking subjects without COPD (both $\mathrm{P}<0.05)$. Out of the smoking COPD subjects, the expression rate of VEGF in the HIF-1 $\alpha$ (+) group $(62.5 \%, 10 / 16)$ was increased compared with in the HIF-1 $\alpha$ (-) group (16.7\%, 3/18; $\mathrm{P}<0.05)$; the expression rate of VEGFR2 in the HIF-1 $\alpha(+)$ group $(68.8 \%, 11 / 16)$ was higher compared with the HIF-1 $\alpha(-)$ group $(22.2 \%, 4 / 18 ; \mathrm{P}<0.05)$. HIF-1 $\alpha$ expression is positively correlated with the expression of VEGF and VEGFR2 ( $\mathrm{r}=0.471$, $\mathrm{P}=0.002 ; \mathrm{r}=0.468, \mathrm{P}=0.003$; Table III). 
A

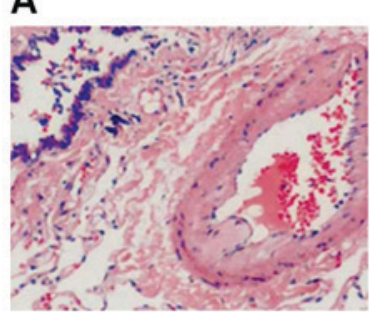

D

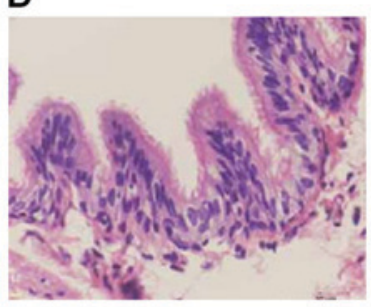

B

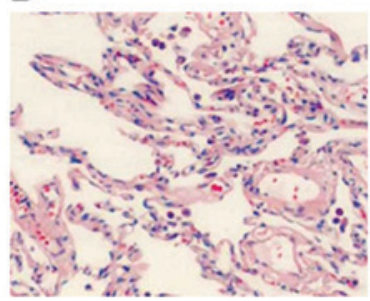

E

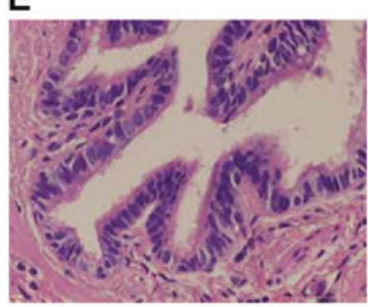

C

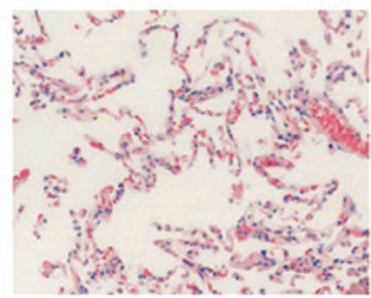

F

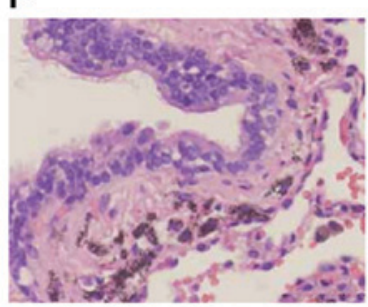

Figure 2. Morphological alterations of the lung tissue, detected by hematoxylin and eosin staining. (A) Lung tissue of non-smoking without COPD group (magnification, x100); (B) lung tissue of smoking without COPD group (magnification, x100); (C) lung tissue of smoking COPD group (magnification, x100); (D) airway tissue of non-smoking without COPD group (magnification, x400); (E) airway tissue of smoking without COPD group (magnification, $x 400$ ); and (F) airway tissue of smoking COPD group (magnification, $x 400$ ). COPD, chronic obstructive pulmonary disease.

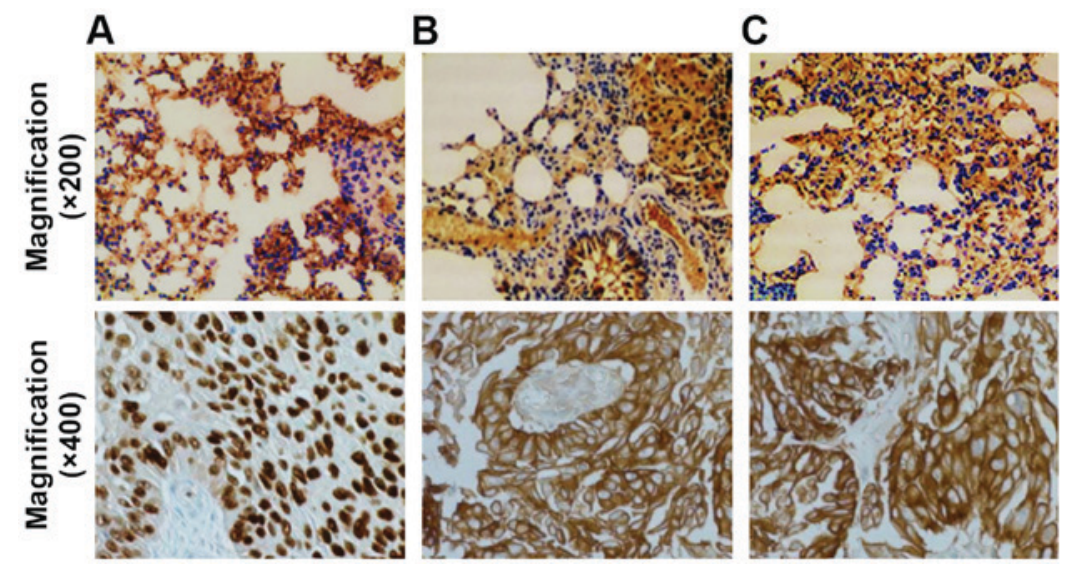

Figure 3. Expression of (A) hypoxia inducible factor-1 $\alpha$, (B) VEGF and (C) VEGF receptor 2 was observed to be increased in the lung epithelium collected from smoking chronic obstructive pulmonary disease subjects, as detected by immunohistochemistry (magnification, x200 and x400 as indicated). VEGF, vascular endothelial growth factor.

Table III. Expression of HIF-1 1 , VEGF and VEGFR2 in COPD patients.

\begin{tabular}{|c|c|c|c|c|c|}
\hline \multirow[b]{2}{*}{ HIF- $1 \alpha$} & \multirow[b]{2}{*}{ Total $\mathrm{n}$} & \multicolumn{2}{|c|}{ VEGF, n (\%) } & \multicolumn{2}{|c|}{ VEGFR2, n (\%) } \\
\hline & & $(+)$ & $(-)$ & $(+)$ & $(-)$ \\
\hline$(+)$ & 16 & $10(62.5)$ & $6(37.5)$ & $11(68.8)$ & $5(31.2)$ \\
\hline$(-)$ & 18 & $3(16.7)^{\mathrm{a}}$ & $15(83.3)^{\mathrm{a}}$ & $4(22.2)^{\mathrm{a}}$ & $14(77.8)^{\mathrm{a}}$ \\
\hline
\end{tabular}

${ }^{a} \mathrm{P}<0.05$ vs. HIF-1 $\alpha(+)$. COPD, chronic obstructive pulmonary disease; HIF-1 $\alpha$, hypoxia-inducible factor-1; VEGF, vascular endothelial growth factor; VEGFR2, vascular endothelial growth factor receptor 2 .

Increased expression of HIF-1 $\alpha, V E G F$ and VEGFR2 reflects the severity of COPD. We investigated the roles of HIF-1 $\alpha$, VEGF and VEGFR2 in developing COPD by western blot analysis. Among the smoking COPD subjects, the protein levels of HIF-1 $\alpha$ and VEGF were increased in males, those with smoking history $\geq 10$ years and those with severity grade of III/IV, compared with females, those with smoking history $<10$ years and those with severity grade of I/II, respectively (all $\mathrm{P}<0.05$ ). The mean expression of VEGFR2 was increased in the smoking COPD patients with severity grade of III/IV compared with those with a severity grade of I/II $(\mathrm{P}<0.05)$. The expression of HIF- $1 \alpha$ and VEGF were not correlated with age, time from symptom onset, history of alcohol use or family history (all P>0.05). VEGFR2 expression was not correlated with age, sex, smoking history, time from symptom onset, history of alcohol use or family history (all P>0.05; Table IV).

Expression of HIF-1 $\alpha, V E G F$ and VEGFR2 increases in relation to declined lung function, reduced quality of life and increased degree of dyspnea in COPD patients. In order to further examine the roles of HIF-1 $\alpha$, VEGF, and VEGFR2 in COPD, we analyzed the protein levels of HIF-1 $\alpha$, VEGF 
Table IV. Expression of HIF-1 $\alpha$, VEGF and VEGFR2, and clinicopathological characteristics in COPD patients.

\begin{tabular}{|c|c|c|c|c|}
\hline Factor & $\mathrm{n}$ & HIF- $1 \alpha$ & VEGF & VEGFR2 \\
\hline \multicolumn{5}{|c|}{ Age (years) } \\
\hline$\geq 60$ & 19 & $0.218 \pm 0.024$ & $0.201 \pm 0.036$ & $0.203 \pm 0.028$ \\
\hline$<60$ & 15 & $0.209 \pm 0.023$ & $0.188 \pm 0.028$ & $0.197 \pm 0.031$ \\
\hline \multicolumn{5}{|l|}{ Sex } \\
\hline Male & 26 & $0.220 \pm 0.023$ & $0.203 \pm 0.031$ & $0.204 \pm 0.025$ \\
\hline Female & 8 & $0.196 \pm 0.018^{\mathrm{a}}$ & $0.170 \pm 0.024^{\mathrm{a}}$ & $0.188 \pm 0.039$ \\
\hline \multicolumn{5}{|c|}{ History of smoking (years) } \\
\hline$\geq 10$ & 23 & $0.221 \pm 0.023$ & $0.203 \pm 0.033$ & $0.203 \pm 0.027$ \\
\hline$<10$ & 11 & $0.199 \pm 0.018^{\mathrm{a}}$ & $0.178 \pm 0.026^{\mathrm{a}}$ & $0.194 \pm 0.034$ \\
\hline \multicolumn{5}{|c|}{ Time from symptom onset (years) } \\
\hline$\geq 5$ & 18 & $0.217 \pm 0.024$ & $0.201 \pm 0.037$ & $0.202 \pm 0.029$ \\
\hline$<5$ & 16 & $0.211 \pm 0.023$ & $0.189 \pm 0.027$ & $0.198 \pm 0.030$ \\
\hline \multicolumn{5}{|c|}{ History of alcohol use } \\
\hline Yes & 11 & $0.222 \pm 0.025$ & $0.203 \pm 0.041$ & $0.204 \pm 0.028$ \\
\hline No & 23 & $0.210 \pm 0.023$ & $0.192 \pm 0.028$ & $0.199 \pm 0.030$ \\
\hline \multicolumn{5}{|c|}{ Family history } \\
\hline Yes & 13 & $0.220 \pm 0.023$ & $0.198 \pm 0.040$ & $0.200 \pm 0.028$ \\
\hline No & 21 & $0.210 \pm 0.024$ & $0.193 \pm 0.028$ & $0.200 \pm 0.030$ \\
\hline \multicolumn{5}{|c|}{ Severity grade } \\
\hline III/IV & 27 & $0.219 \pm 0.022$ & $0.203 \pm 0.031$ & $0.207 \pm 0.028$ \\
\hline $\mathrm{I} / \mathrm{II}$ & 7 & $0.193 \pm 0.017^{\mathrm{a}}$ & $0.164 \pm 0.019^{a}$ & $0.176 \pm 0.021^{\mathrm{a}}$ \\
\hline
\end{tabular}

${ }^{a} \mathrm{P}<0.05$ vs. the other index in the same protein. COPD, chronic obstructive pulmonary disease; HIF-1 $\alpha$, hypoxia-inducible factor- $1 \alpha$; VEGF, vascular endothelial growth factor; VEGFR2, vascular endothelial growth factor receptor 2.

Table V. Association between the expression of HIF-1 $\alpha$, VEGF and VEGFR2, and PFT, CAT scores and mMRC grades in COPD patients.

\begin{tabular}{lccc}
\hline Item & HIF- $1 \alpha$ & VEGF & VEGFR2 \\
\hline FEV1 (1) & $\mathrm{r}=-0.624, \mathrm{P}<0.001$ & $\mathrm{r}=-0.711, \mathrm{P}<0.001$ & $\mathrm{r}=-0.646, \mathrm{P}<0.001$ \\
FEV1\% pred & $\mathrm{r}=-0.740, \mathrm{P}<0.001$ & $\mathrm{r}=-0.730, \mathrm{P}<0.001$ & $\mathrm{r}=-0.735, \mathrm{P}<0.001$ \\
FVC\% pred & $\mathrm{r}=-0.664, \mathrm{P}<0.001$ & $\mathrm{r}=-0.550, \mathrm{P}<0.001$ & $\mathrm{r}=-0.568, \mathrm{P}<0.001$ \\
FEV1/FVC\% & $\mathrm{r}=-0.826, \mathrm{P}<0.001$ & $\mathrm{r}=-0.695, \mathrm{P}<0.001$ & $\mathrm{r}=-0.712, \mathrm{P}<0.001$ \\
PEF\% pred & $\mathrm{r}=-0.800, \mathrm{P}<0.001$ & $\mathrm{r}=-0.670, \mathrm{P}<0.001$ & $\mathrm{r}=-0.694, \mathrm{P}<0.001$ \\
CAT scores & $\mathrm{r}=0.533, \mathrm{P}<0.001$ & $\mathrm{r}=0.594, \mathrm{P}<0.001$ & $\mathrm{r}=0.598, \mathrm{P}<0.001$ \\
mMRC grades & $\mathrm{r}=0.450, \mathrm{P}=0.004$ & $\mathrm{r}=0.579, \mathrm{P}<0.001$ & $\mathrm{r}=0.509, \mathrm{P}=0.001$ \\
\hline
\end{tabular}

COPD, chronic obstructive pulmonary disease; CAT, COPD Assessment Test; mMRC, Modified Medical Research Council; HIF-1 $\alpha$, hypoxia-inducible factor-1 $\alpha$; VEGF, vascular endothelial growth factor; VEGFR2, vascular endothelial growth factor receptor 2; FEV1, forced expiratory volume in $1 \mathrm{sec}$; pred, predicted; FVC, forced vital capacity; PEF, peak expiratory flow.

and VEGFR2 in relation to lung functions, quality of life and degree of dyspnea. The protein level of HIF-1 $\alpha$ was negatively correlated with FEV1 (L), FEV1\% pred, FVC\% pred, FEV1/FVC $\%$ and $\mathrm{PEF} \%$ pred $(\mathrm{r}=-0.624, \mathrm{P}<0.001 ; \mathrm{r}=-0.740$, $\mathrm{P}<0.001 ; \mathrm{r}=-0.664, \mathrm{P}<0.001 ; \mathrm{r}=-0.826, \mathrm{P}<0.001 ; \mathrm{r}=-0.800$, $\mathrm{P}<0.001$, respectively), while it was positively correlated with CAT scores and $\mathrm{mMRC}$ grades $(\mathrm{r}=0.533, \mathrm{P}<0.001 ; \mathrm{r}=0.450$, $\mathrm{P}=0.004$, respectively). A negative correlation was identified between the protein level of VEGF and FEV1 (L), FEV1\% pred, FVC $\%$ pred, FEV1/FVC $\%$ and $\mathrm{PEF} \%$ pred $(\mathrm{r}=-0.711$, $\mathrm{P}<0.001 ; \mathrm{r}=-0.730, \mathrm{P}<0.001 ; \mathrm{r}=-0.550, \mathrm{P}<0.001 ; \mathrm{r}=-0.695$, $\mathrm{P}<0.001 ; \mathrm{r}=-0.670, \mathrm{P}<0.001$, respectively), while the protein level of VEGF was positively correlated with CAT scores and $\mathrm{mMRC}$ grades $(\mathrm{r}=0.594, \mathrm{P}<0.001 ; \mathrm{r}=0.579, \mathrm{P}<0.001)$. VEGFR2 expression was determined to be negatively correlated with FEV1 (L), FEV1\% pred, FVC\% pred, FEV1/FVC\% 
and $\mathrm{PEF} \%$ pred $(\mathrm{r}=-0.646, \mathrm{P}<0.001 ; \mathrm{r}=-0.735, \mathrm{P}<0.001$; $\mathrm{r}=-0.568, \mathrm{P}<0.001 ; \mathrm{r}=-0.712, \mathrm{P}<0.001 ; \mathrm{r}=-0.694, \mathrm{P}<0.001$ ), and positively correlated with CAT scores and mMRC grades $(\mathrm{r}=0.598, \mathrm{P}<0.001 ; \mathrm{r}=0.509, \mathrm{P}=0.001 ;$ Table V).

\section{Discussion}

COPD is a condition that is not fully reversible and it is a critical cause of morbidity and mortality worldwide $(2,3)$. Tobacco smoking has been reported to be a major risk factor for COPD $(19,20)$. The present study was performed to explore the expression of HIF-1 signaling pathway-related proteins (HIF-1 $\alpha$, VEGF and VEGFR2) in subjects without COPD both smoking and non-smoking and smoking COPD subjects, and their association with the clinicopathological characteristics of COPD patients.

Pulmonary function tests were conducted and CAT and mMRC scales were used to determine lung functions, quality of life and degree of dyspnea among smoking COPD subjects, and non-smoking and smoking subjects without COPD. We found declined lung function, reduced quality of life and an increased degree of dyspnea in smoking COPD subjects. These findings in particular are largely corroborated by a previous study, where the rate of lung function decline was augmented in continued smoking COPD subjects, and the decline was increased in the GOLD II/III stages, which highlights the clinical value of early smoking cessation (21). The mechanism that was reported by Barnes (9), indicated that smoking may facilitate systemic inflammation and accelerate leukocytes, and smoking COPD patients suffer from more systemic inflammation. On the other hand, Sundar et al (22) demonstrated that smoking exacerbates COPD by triggering oxidative stress and chromatin remodeling. Active smoking facilitates systemic inflammation in smoking and non-smoking COPD patients, and smoking should always be analyzed in studies on the pathogenesis of COPD (23). Elevated airway inflammation promotes lung function decline, and FEV1 decline is enhanced by the duration and intensity of smoking in continual smokers $(24,25)$. Symptoms and clinical signs of COPD reduce quality of life through chronic cough, shortness of breath and wheezing (6). Furthermore, it has been documented that patients with COPD may suffer from disability, which is caused by such specific functional limitations as reduced mobility, decreased exercise performance, weakness in skeletal muscles and a damaged lower extremity function (26).

Immunohistochemistry and western blot analysis in this study demonstrated that the expression of HIF- $1 \alpha$, VEGF and VEGFR2 was increased in lung tissues collected from smoking COPD subjects compared with non-smoking subjects without COPD and smoking subjects without COPD. Increased expression of HIF-1 $\alpha$, VEGF, and VEGFR2 reflected the disease severity of COPD. As stated in the study of Chen et al (27), HIF-1 $\alpha$ gene expression is implicated in the progression of hypoxic pulmonary vascular remodeling under the regulation of prolyl hydroxylase in COPD. HIF-1 $\alpha$ expression is low under conditions of normal oxygen supply since the stimulation of prolyl hydroxylases hydroxylate HIF-1 $\alpha$ at Pro-402 and Pro-564 (28). Activity of HIF-1 is stimulated by hypoxia through the changes in expression of HIF- $1 \alpha$ mRNA and protein (12), which has been revealed in non-small cell lung cancer (29), lung adenocarcinoma cancer (29) and hypoxic pulmonary hypertension (30). Specifically, HIF-1 $\alpha$ moves to the nucleus and dimerizes with HIF-1 $\beta$ under conditions of hypoxia, and then stimulates transcription of target genes with hypoxia-sensitive elements in the promoter region; meanwhile, the HIF signaling pathway attenuates mucus production in COPD by mediating the differentiation of airway epithelial cells (31). Moreover, the hypoxia-triggered activation of HIF and increased VEGF expression in pulmonary artery smooth muscle cells indicates that the HIF signaling pathway augments the vasculopathy of pulmonary arterial hypertension through involvement of nitric oxide alterations and corresponding metabolic changes $(32,33)$. Corroborating results identified in this study were that HIF-1 $\alpha$ expression was positively correlated with expression of VEGF and VEGFR2. VEGF is a crucial angiogenic growth factor and abnormal expression of VEGFRs may cause emphysema or chronic hypoxia $(34,35)$. The expression of VEGF is elevated in the pulmonary muscular arteries of COPD patients and smokers, and this aberrant expression alteration is associated with the wall enlargement of pulmonary arteries $(36,37)$. Airway inflammatory cells and alveolar epithelial cells may be a major source of inflammatory mediators, cytokines and growth factors, including VEGF, and increased VEGF expression is likely to contribute to the pathogenesis of inflammatory lung diseases and to the angiogenic phenotype of lung cancer, a disease typically preceded by chronic inflammation (38). VEGF expression is up-regulated by hypoxia (39) and overexpression of VEGF and its receptors was also proposed to contribute to peripheral vascular and airway remodeling processes (14), which is the principal mechanism underlying COPD. The positive correlation between HIF-1 $\alpha$ and VEGF and VEGFR2 has been supported by a study by Ioannou et al (40), which showed that VEGF expression in small cell lung cancer reflects transcriptional activation regulated by HIF- $1 \alpha$. As a COPD phenotype, chronic bronchitis also causes increased expression of VEGF and HIF-1 $\alpha$ in lung tissues, and they are positively correlated (13).

In conclusion, the HIF-1 signaling pathway was activated in smokers with COPD, and the over-expression of related proteins such as HIF-1 $\alpha$, VEGF and VEGFR2 was associated with a decrease of lung function, reduced quality of life and progression of COPD. However, further studies are needed to assess the pre-cessation and post-cessation clinicopathological characteristics of smoking COPD patients. As a result of the present study, the HIF-1 signaling pathway may be proposed as a potential target for the treatment of COPD.

\section{Acknowledgements}

Not applicable.

\section{Funding}

No funding was received.

\section{Availability of data and materials}

The datasets used and/or analyzed during the current study are available from the corresponding author on reasonable request. 


\section{Authors' contributions}

XF designed the study, researched the literature, collected the patient data and wrote the draft of the manuscript. FZ analyzed the data, produced the figures and participated in writing the manuscript. All authors read and approved the final manuscript.

\section{Ethics approval and consent to participate}

The present study was performed with the approval of the Ethics Committee of The No. 5 Hospital of Xiamen (Xiamen, Fujian, China). Written informed consent and the required documentation were obtained from each patient and respective guardians prior to the study.

\section{Consent for publication}

Written informed consent was obtained for the publication of patient data and images.

\section{Competing interests}

The authors declare that they have no competing interests.

\section{References}

1. Vestbo J, Hurd SS and Rodriguez-Roisin R: The 2011 revision of the global strategy for the diagnosis, management and prevention of COPD (GOLD)-why and what? Clin Respir J 6: 208-214, 2012.

2. Duvoix A, Dickens J, Haq I, Mannino D, Miller B, Tal-Singer R and Lomas DA: Blood fibrinogen as a biomarker of chronic obstructive pulmonary disease. Thorax 68: 670-676, 2013.

3. Guo Y, Zhang T, Wang Z, Yu F, Xu Q, Guo W, Wu C and He J: Body mass index and mortality in chronic obstructive pulmonary disease: A dose-response meta-analysis. Medicine (Baltimore) 95: e4225, 2016.

4. Bhatt SP and Dransfield MT: Chronic obstructive pulmonary disease and cardiovascular disease. Trans1 Res 162: 237-251, 2013

5. Rabe KF and Watz H: Chronic obstructive pulmonary disease Lancet 389: 1931-1940, 2017.

6. Russi EW, Karrer W, Brutsche M, Eich C, Fitting JW, Frey M, Geiser T, Kuhn M, Nicod L, Quadri F, et al: Diagnosis and management of chronic obstructive pulmonary disease: The Swiss guidelines. Official guidelines of the Swiss Respiratory Society. Respiration 85: 160-174, 2013.

7. Casanova C,Marin JM, Martinez-Gonzalez C, de Lucas-Ramos P, Mir-Viladrich I, Cosio B, Peces-Barba G, Solanes-García I, Agüero R, Feu-Collado N, et al: Differential effect of modified medical research council dyspnea, COPD assessment test, and clinical COPD questionnaire for symptoms evaluation within the new GOLD staging and mortality in COPD. Chest 148: 159-168, 2015.

8. Fullerton DG, Gordon SB and Calverley PM: Chronic obstructive pulmonary disease in non-smokers. Lancet 374: 1964-1966, 2009

9. Barnes PJ: Cellular and molecular mechanisms of chronic obstructive pulmonary disease. Clin Chest Med 35: 71-86, 2014.

10. Zhao X, Gao S, Ren H, Sun W, Zhang H, Sun J, Yang S and Hao J: Hypoxia-inducible factor-1 promotes pancreatic ductal adenocarcinoma invasion and metastasis by activating transcription of the actin-bundling protein fascin. Cancer Res 74: 2455-2464, 2014.

11. Gui D, Li Y, Chen X, Gao D, Yang Y and Li X: HIF-1 signaling pathway involving iNOS, COX-2 and caspase- 9 mediates the neuroprotection provided by erythropoietin in the retina of chronic ocular hypertension rats. Mol Med Rep 11: 1490-1496, 2015.

12. Semenza GL: Hypoxia-inducible factor 1 and cardiovascular disease. Annu Rev Physiol 76: 39-56, 2014.

13. Lee SH, Lee SH, Kim CH, Yang KS, Lee EJ, Min KH, Hur GY, Lee SH, Lee SY, Kim JH, et al: Increased expression of vascular endothelial growth factor and hypoxia inducible factor- $1 \alpha$ in lung tissue of patients with chronic bronchitis. Clin Biochem 47: 552-559, 2014.
14. Kranenburg AR, de Boer WI, Alagappan VK, Sterk PJ and Sharma HS: Enhanced bronchial expression of vascular endothelial growth factor and receptors (Flk-1 and Flt-1) in patients with chronic obstructive pulmonary disease. Thorax 60: 106-113, 2005.

15. Johannessen A, Nilsen RM, Storebø M, Gulsvik A, Eagan T and Bakke P: Comparison of 2011 and 2007 Global Initiative for Chronic Obstructive Lung Disease guidelines for predicting mortality and hospitalization. Am J Respir Crit Care Med 188: 51-59, 2013.

16. Yu WC, Fu SN, Tai EL, Yeung YC, Kwong KC, Chang Y, Tam CM and Yiu YK: Spirometry is underused in the diagnosis and monitoring of patients with chronic obstructive pulmonary disease (COPD). Int J Chron Obstruct Pulmon Dis 8: 389-395, 2013.

17. Jones PW, Harding G, Berry P, Wiklund I, Chen WH and Kline Leidy N: Development and first validation of the COPD assessment test. Eur Respir J 34: 648-654, 2009.

18. Ma Y, Ma L, Guo Q and Zhang S: Expression of bone morphogenetic protein-2 and its receptors in epithelial ovarian cancer and their influence on the prognosis of ovarian cancer patients. J Exp Clin Cancer Res 29: 85, 2010

19. Salvi S: Tobacco smoking and environmental risk factors for chronic obstructive pulmonary disease. Clin Chest Med 35: 17-27, 2014

20. Burney P, Jithoo A, Kato B, Janson C, Mannino D, Nizankowska-Mogilnicka E, Studnicka M, Tan W, Bateman E, Koçabas A, et al: Chronic obstructive pulmonary disease mortality and prevalence: The associations with smoking and poverty-a BOLD analysis. Thorax 69: 465-473, 2014.

21. Lange P, Celli B, Agustí A, Boje Jensen G, Divo M, Faner R, Guerra S, Marott JL, Martinez FD, Martinez-Camblor P, et al: Lung-function trajectories leading to chronic obstructive pulmonary disease. N Engl J Med 373: 111-122, 2015.

22. Sundar IK, Yao H and Rahman I: Oxidative stress and chromatin remodeling in chronic obstructive pulmonary disease and smoking-related diseases. Antioxid Redox Signal 18: 1956-1971, 2013.

23. Pelegrino NR, Tanni SE, Amaral RA, Angeleli AY, Correa C and Godoy I: Effects of active smoking on airway and systemic inflammation profiles in patients with chronic obstructive pulmonary disease. Am J Med Sci 345: 440-445, 2013.

24. Higashimoto Y, Iwata T, Okada M, Satoh H, Fukuda K and Tohda Y: Serum biomarkers as predictors of lung function decline in chronic obstructive pulmonary disease. Respir Med 103: 1231-1238, 2009.

25. Donaldson GC, Seemungal TA, Bhowmik A and Wedzicha JA: Relationship between exacerbation frequency and lung function decline in chronic obstructive pulmonary disease. Thorax 57: 847-852, 2002

26. Eisner MD, Iribarren C, Yelin EH, Sidney S, Katz PP, Ackerson L, Lathon P, Tolstykh I, Omachi T, Byl N and Blanc PD: Pulmonary function and the risk of functional limitation in chronic obstructive pulmonary disease. Am J Epidemiol 167: 1090-1101, 2008.

27. Chen YR, Dai AG, Hu RC and Kong CC: The expression of hypoxia-inducible factor-1alpha and its hydroxylases in pulmonary arteries of patient with chronic obstructive pulmonary disease. Zhongguo Ying Yong Sheng Li Xue Za Zhi 28: 234-238, 2012 (In Chinese).

28. Nguyen LK, Cavadas MA, Scholz CC, Fitzpatrick SF, Bruning U, Cummins EP, Tambuwala MM, Manresa MC, Kholodenko BN, Taylor CT and Cheong A: A dynamic model of the hypoxia-inducible factor $1 \alpha$ (HIF-1 $\alpha$ ) network. J Cell Sci 126: 1454-1463, 2013.

29. Zhang L, Ge W, Hu K, Zhang Y, Li C, Xu X, He D, Zhao Z, Zhang J, Jie F, et al: Endostar down-regulates HIF-1 and VEGF expression and enhances the radioresponse to human lung adenocarcinoma cancer cells. Mol Biol Rep 39: 89-95, 2012.

30. Jiang Y, Wang J, Tian H, Li G, Zhu H, Liu L, Hu R and Dai A: Increased SUMO-1 expression in response to hypoxia: Interaction with HIF-1 $\alpha$ in hypoxic pulmonary hypertension. Int J Mol Med 36: 271-281, 2015.

31. Polosukhin VV, Cates JM, Lawson WE, Milstone AP, Matafonov AG, Massion PP, Lee JW, Randell SH and Blackwell TS: Hypoxia-inducible factor-1 signalling promotes goblet cell hyperplasia in airway epithelium. J Pathol 224: 203-211, 2011.

32. Fijalkowska I, Xu W, Comhair SA, Janocha AJ, Mavrakis LA, Krishnamachary B, Zhen L, Mao T, Richter A, Erzurum SC and Tuder RM: Hypoxia inducible-factorlalpha regulates the metabolic shift of pulmonary hypertensive endothelial cells. Am J Pathol 176: 1130-1138, 2010. 
33. Hosford GE and Olson DM: Effects of hyperoxia on VEGF, its receptors, and HIF-2alpha in the newborn rat lung. Am J Physiol Lung Cell Mol Physiol 285: L161-L168, 2003.

34. Kasahara Y, Tuder RM, Taraseviciene-Stewart L, Le Cras TD, Abman S, Hirth PK, Waltenberger J and Voelkel NF: Inhibition of VEGF receptors causes lung cell apoptosis and emphysema. J Clin Invest 106: 1311-1319, 2000.

35. Tipoe GL and Fung ML: Expression of HIF-1alpha, VEGF and VEGF receptors in the carotid body of chronically hypoxic rat. Respir Physiol Neurobiol 138: 143-154, 2003.

36. Jiang H, Zhu Y, Xu H, Sun Y and Li Q: Activation of hypoxiainducible factor-1alpha via nuclear factor-kappa $B$ in rats with chronic obstructive pulmonary disease. Acta Biochim Biophys Sin (Shanghai) 42: 483-488, 2010.

37. Yamaji-Kegan K, Su Q, Angelini DJ, Champion HC and Johns RA Hypoxia-induced mitogenic factor has proangiogenic and proinflammatory effects in the lung via VEGF and VEGF receptor-2. Am J Physiol Lung Cell Mol Physiol 291: L1159-L1168, 2006.
38. Maloney JP and Gao L: Proinflammatory cytokines increase vascular endothelial growth factor expression in alveolar epithelial cells. Mediators Inflamm 2015: 387842, 2015.

39. McCarty G, Awad O and Loeb DM: WT1 protein directly regulates expression of vascular endothelial growth factor and is a mediator of tumor response to hypoxia. J Biol Chem 286: 43634-43643, 2011.

40. Ioannou M, Papamichali R, Kouvaras E, Mylonis I, Vageli D, Kerenidou T, Barbanis S, Daponte A, Simos G, Gourgoulianis K and Koukoulis GK: Hypoxia inducible factor- 1 alpha and vascular endothelial growth factor in biopsies of small cell lung carcinoma. Lung 187: 321-329, 2009.

This work is licensed under a Creative Commons Attribution-NonCommercial-NoDerivatives 4.0 International (CC BY-NC-ND 4.0) License. 